Celso Zilbovicius ${ }^{1}$ Regina Glaucia Lucena Aguiar Ferreira ${ }^{2}$ Paulo Capel Narvai ${ }^{1}$

\title{
ÁGUA E SAÚDE: FLUORETAÇÃO E REVOGAÇÃO DA LEI FEDERAL N. 6.050/1974
}

Water and health: fluoridation and the repeal of Brazilian Federal Law 6050/74

${ }^{1}$ Universidade de São Paulo. São Paulo/SP, Brasil.

${ }^{2}$ Universidade Federal do Ceará. Fortaleza/CE, Brasil.

Correspondência: Celso Zilbovicius. E-mail: czilbo@usp.br.

Recebido: 02/02/2016. Revisado: 18/05/2016. Aprovado: 29/05/2016. 


\section{RESUMO}

Ao contrário de muitos países, o Brasil dispõe de um instrumento legal que ampara a fluoretação da água (uma tecnologia de saúde pública eficaz para prevenir a cárie dentária em nível populacional): a Lei Federal n. 6.050/1974. Como não há objeções científicas à medida, o país deveria proteger esse instrumento. Contudo, a Câmara dos Deputados tem acolhido iniciativas parlamentares que pedem a revogação da lei brasileira que torna a medida obrigatória onde haja estação de tratamento de água. Tal é o caso dos projetos de lei n. 510/2003 e n. $6.359 / 2013$. Neste artigo, são analisados os argumentos que justificam esses projetos de leis, à luz de evidências científicas. Constatou-se estreita semelhança entre os conteúdos dos dois projetos: os argumentos utilizados para justificar a revogação da lei não têm embasamento científico e se apoiam apenas em crendices e no senso comum. A fluoretação de águas de abastecimento tornou-se, ao longo do século XX, a ação de maior impacto na prevenção da cárie. No Brasil, a referida lei tornou-se um referencial jurídico importante para a implantação da fluoretação em boa parte do território nacional, beneficiando milhões de pessoas de todas as idades e contribuindo para atenuar as limitações de acesso às ações de prevenção individuais e à assistência odontológica. Conclui-se que a revogação da lei implicaria, em muitos casos, a suspensão dessa importante medida sanitária, configurando-se um ato de injustiça, com o aprofundamento de desigualdades decorrente da previsível piora do quadro epidemiológico bucal.

\section{Palavras-Chave}

Água de Abastecimento; Fluoretação; Legislação Sanitária.

\section{ABSTRACT}

Unlike many countries, Brazil has a legal instrument that endorses water fluoridation, an effective public health technology to prevent tooth decay of the population: Federal Law $6050 / 1974$. As there are no scientific objections to the measure, the country should protect this instrument. However, the Chamber of Deputies has welcomed parliamentary initiatives calling for the repeal of the Brazilian law which mandates fluoridation wherever there is a water treatment plant. Such were the cases of the Bill 510, in 2003, and the Bill 6359, in 2013. In this article we analyze the arguments justifying these bills, in the light of scientific evidence. It was found close similarity between the contents of the two bills: the arguments used to justify the repeal of the law have no scientific basis and rely only on beliefs and common sense. The supply of water fluoridation has become the action with the greatest impact in preventing tooth decay, throughout the twentieth century. In Brazil, this law has become an important legal frame of reference for its implementation in much of the country, benefiting millions of people of all ages, helping to mitigate the limitations of access to individual preventative actions and dental care. It was concluded that the repeal of this law would imply in the suspension of an important health measure representing an injustice and bringing about inequalities and a foreseeable worsening of the oral epidemiological framework.

\section{Keywords}

Fluoridation; Health Legislation; Water Supply. 


\section{Introdução}

A fluoretação das águas na estação de tratamento é obrigatória no Brasil desde 1974, segundo a Lei Federal n. 6.050/1974', porém, somente no ano seguinte, foram estabelecidos os padrões para a operacionalização da medida (Portaria n. $635 / 1975)^{2}$, tais como os limites recomendados para a concentração do fluoreto.

Dois anos depois da aprovação da lei federal da fluoretação, o Ministério da Saúde aprovou normas e critérios de padrão de potabilidade da água, mediante a Portaria n. 56/1977³, fixando em 1,7 mg F/L o Valor Máximo Permissível (VMP) de fluoreto em águas de consumo humano. Em 2000, o VMP foi alterado para 1,5 mg F/L pela Portaria n. 1.469/20004, valor mantido na Portaria n. 518/20045.

A Lei Federal n. 6.050/1974 teve enorme impacto no processo de fluoretação das águas de abastecimento público, cujo início se dera no Brasil em 1953 - quando o pioneiro sistema de Baixo Guandu, no Espírito Santo, fora inaugurado. Até 1974, foi lenta a adoção da medida pelos municípios e frágil, o apoio do governo federal. A partir de 1974, o panorama se alterou profundamente, com a norma legal amparando iniciativas relevantes tomadas por municípios e estados interessados em beneficiar suas populações com essa medida. O governo federal interveio com recursos financeiros, e essa combinação de esforços resultou na inserção do Brasil no rol de países com ampla cobertura populacional de água fluoretada, ao lado de Estados Unidos, Canadá, Austrália e Nova Zelândia, dentre outros.

Desde a aprovação da Lei n. 6.050/1974, tem sido observada notável expansão da medida em todo o país, embora essa implementação seja marcada por importantes desigualdades regionais. É destacável sua contribuição nos esforços para prevenir e controlar a cárie em nível populacional no Brasil: a epidemiologia dessa doença se alterou profundamente nas últimas cinco décadas, notadamente nas regiões mais beneficiadas, e há reconhecimento de que, pelo menos em parte, essa alteração é devida ao papel desempenhado pela fluoretação da água.

${ }^{1}$ BRASIL. Lei n. 6.050, de 24 de maio de 1974. Dispõe sobre a fluoretação da água em sistemas de abastecimento quando existir estação de tratamento. Disponível em: <http://www.planalto.gov.br/ ccivil_03/leis/L6050.htm>. Acesso em: 02 fev. 2018.

${ }^{2}$ BRASIL. Ministério da Saúde. Portaria n. 635/Bsb, de 26 de dezembro de 1975. Aprova normas e padrões sobre a fluoretação da água de sistemas públicos de abastecimento. Disponível em: <https://central3. to.gov.br/arquivo/349893/>. Acesso em: 02 fev. 2018.

${ }^{3}$ BRASIL. Ministério da Saúde. Portaria n. 56/Bsb, de 14 de março de 1977. Aprova normas e o padrão de potabilidade da água a serem observados em todo o território nacional. Diário Oficial União, 22 mar. 1977. 4BRASIL. Ministério da Saúde. Portaria n. 1.469, de 29 de dezembro de 2000. Estabelece os procedimentos e responsabilidades relativos ao controle e vigilância da qualidade da água para consumo humano e seu padrão de potabilidade, e dá outras providências. Disponível em: <http://portalarquivos2.saude.gov.br/ images/pdf/2015/setembro/30/Portaria-MS-1469-00.pdf>. Acesso em: 02 fev. 2018.

${ }^{5}$ BRASIL. Ministério da Saúde. Portaria n. 518, de 25 de março de 2004. Estabelece os procedimentos e esponsabilidades relativas ao controle e vigilância da qualidade da água para o consumo humano e seu padrão de potabilidade, e dá outras providências. Diário Oficial União, 16 mar. 2004; Seção 1:266-70. 
Não obstante seus comprovados benefícios, a Câmara dos Deputados tem acolhido, periodicamente, iniciativas parlamentares que pedem a revogação da Lei n. 6.050/1974. Tal foi o caso do Projeto de Lei (PL) n. 510/20036, e também do PL n. 6.359/20137 , apesar de o Conselho Regional de Odontologia de São Paulo ter solicitado o arquivamento deste último PL à Comissão de Constituição e Justiça e de Cidadania da Câmara ${ }^{8}$.

No presente estudo, analisam-se os argumentos que justificam esses dois PLs quanto às bases científicas que supostamente lhes dariam sustentação.

\section{Método}

Trata-se de pesquisa qualitativa, do tipo análise documental, com foco nas justificações do PL n. 510/2003 e do PL n. 6.359/2013, cujos dados foram tratados por meio da análise de conteúdo. O processo de formação das categorias ocorreu a partir das unidades de registro, como preconizado por Bardin ${ }^{9}$, em uma etapa denominada "exploração", a qual foi precedida pela "pré-análise" do material coletado. Na terceira e última etapa, fez-se o "tratamento dos resultados". Empregou-se neste estudo a modalidade "temática" de análise de conteúdo.

Após a constatação da grande semelhança entre os dois documentos (PL n. 510/2003 e PL n. 6.359/2013), procedeu-se à pré-análise de forma alinhada e à definição do corpus de análise, o que resultou na identificação das unidades de registro e na elaboração das categorias de análise descritas a seguir. Com exceção da Categoria V (o mecanismo dos benefícios do flúor é principalmente tópico), que diz respeito apenas ao PL n. 6.395/2013, as demais categorias de análise surgiram a partir das justificações de ambos os PLs.

\section{Fluoretação da água: um equívoco científico}

Justificação dos PLs ns. 510/2003 e 6.359/2013:

A fluoretação da água para abastecimento público, tornada obrigatória em vários países e até objeto de campanhas por órgãos

\footnotetext{
${ }^{6}$ BRASIL. Câmara dos Deputados. Projeto de Lei n. 510/2003. Revoga a Lei n. 6.050, de 24 de maio de 1974, que "dispõe sobre a fluoretação da água em sistemas de abastecimento quando existir estação de tratamento". Disponível em: <http://www.camara.gov.br/proposicoesWeb/prop_mostrarintegra;jsess ionid=4FE1764024000A04D13CA4223B999374. proposicoesWebExterno2 ?codteor=120335\&filename= PL+510/2003>. Acesso em: 02 fev. 2018.

${ }^{7}$ BRASIL. Câmara dos Deputados. Projeto de Lei n. 6.359/2013. Revoga a Lei n. 6.050, de 24 de maio de 1974, que "dispõe sobre a fluoretação da água em sistemas de abastecimento quando existir estação de tratamento". Disponível em: <http://www.camara.gov.br/proposicoesWeb/prop_mostrarintegra?codteor= 1135909\&filename=PL+6359/2013>. Acesso em: 02 fev. 2018.

${ }^{8}$ CONSELHO REGIONAL DE ODONTOLOGIA DE SÃO PAULO. Ofício Pres. 002569/2014: Encaminha solicitação ao Deputado Federal Dr. Vicente Cândido da Silva, presidente da Comissão de Constituição e Justiça e de Cidadania. São Paulo, 2014.

9BARDIN, Laurence. Análise de conteúdo. Lisboa: Edições 70, LDA, 2009.
} 
internacionais de saúde pública, é fruto de um equívoco científico. A prevenção da cárie dentária foi o pretexto para iniciar-se a adição de cloro na água destinada ao consumo humano. Tal fato teve origem ainda no final do século XIX, quando foi observada a baixíssima incidência de cáries em populações de localidades britânicas onde a água continha, naturalmente, flúor.

[...]

A adição de flúor à água utilizada para consumo humano passou, a partir do final da década de 1960, a ser considerada como uma verdadeira panaceia, que iria livrar as pessoas das cáries dentárias. Campanhas foram promovidas e programas, instituídos, inclusive pela Organização Mundial da Saúde e pelo nosso Ministério da Saúde. No Brasil, as campanhas de prevenção da cárie dentária, mediante a ingestão pelas pessoas de uma quantidade mínima diária de flúor, culminaram com o estabelecimento, pela Lei n. 6.050 , de 24 de maio de 1974, da obrigatoriedade de que, nas estações de tratamento de água destinada ao abastecimento público, fosse adicionado flúor à água. É esta lei que estamos propondo revogar ${ }^{10}, 11$.

\section{Fluoretação da água de abastecimento: mais malefícios à saúde do que benefícios}

Justificação dos PLs ns. 510/2003 e 6.359/2013:

Posteriormente, constatou-se que a ingestão elevada dessa substância provocava fluorose, doença óssea que se caracteriza pelo aparecimento de manchas e estrias escuras nos dentes. Além dos efeitos estéticos, a fluorose torna os dentes porosos e quebradiços.

[...]

A partir de estudos científicos aprofundados e de inúmeros fatos verificados entre as populações que consomem água fluoretada, constatou-se que, ao contrário do que se supunha, a fluoretação provoca muito mais males que benefícios à saúde pública, ao promover a ingestão excessiva e indiscriminada de flúor.

[...]

A fluorose é a principal doença causada pela ingestão excessiva de flúor. Além dos problemas dentários que já citamos, ela provoca perda de cálcio dos ossos e envelhecimento precoce das pessoas. Tais efeitos foram amplamente comprovados no estado de Rajasthan, na Índia, onde águas de poços utilizados para o

${ }^{10}$ BRASIL. Câmara dos Deputados. Projeto de Lei n. 503/2003, cit.

${ }^{11}$ BRASIL. Câmara dos Deputados. Projeto de Lei n. 6.359/2013, cit. 
abastecimento de vários povoados contêm elevados teores de flúor. Nas populações desses povoados, segundo o Centro de Pesquisa sobre Fluorose e Desenvolvimento Rural de Nova Délhi, veem-se claramente os efeitos nocivos do flúor, consistindo a fluorose em um sério problema de saúde pública. Nos Estados Unidos, o Dr. William Marcus, toxicologista da Environmental Protection Agency (EPA) - a agência ambiental federal daquele país -, detectou estreita correlação entre o crescimento dos casos de um tipo de câncer ósseo, o osteossarcoma, e a ingestão de flúor. Outro estudo, realizado no estado de Nova Jersey, comparou a incidência desse tipo de câncer em vários municípios, concluindo que era maior onde era feita a fluoretação. Esse tipo de câncer atinge, principalmente, rapazes com menos de vinte anos de idade $^{12},{ }^{13}$.

\section{Imprecisão quanto à dosagem do fluoreto}

Justificação dos PLs ns. 510/2003 e 6.359/2013:

Um dos problemas mais sérios da fluoretação da água para abastecimento público é a imprecisão quanto à dosagem dessa substância [...]. Pesquisas levaram à conclusão de que a dosagem ótima de flúor na água seria da ordem de 0,7 ppm a 1 ppm (ppm é a abreviatura de partes por milhão) e que o flúor só era eficaz como preventivo contra as cáries se ingerido na fase de crescimento ósseo-dentário das pessoas [...].

$[\ldots]$

Como o flúor é aplicado normalmente sob a forma de sais de difícil solubilidade, em geral o fluorsilicato de sódio, a sua concentração na água varia enormemente. Pesquisas realizadas pela Dra. Marília Afonso Rabelo Buzalaf, da Faculdade de Odontologia de Bauru, no Estado de São Paulo, no sistema de distribuição de água daquela cidade, mostraram enormes variações nas concentrações de flúor da água, que, em geral, eram muito inferiores à recomendada e, algumas vezes, muito superiores, atingindo até 9 ppm (nove vezes o máximo recomendado). As concentrações muito baixas fazem a fluoretação ineficaz, enquanto que aquelas muito elevadas sujeitam os consumidores da água à ação tóxica do flúor. A água fluoretada é um problema também quando utilizada no preparo caseiro de alimentos e na indústria alimentícia. Isto porque a maior parte da água empregada no cozimento de alimentos e em processos industriais é evaporada, deixando os

\footnotetext{
${ }^{12}$ BRASIL. Câmara dos Deputados. Projeto de Lei n. 503/2003, cit.

${ }^{13}$ BRASIL. Câmara dos Deputados. Projeto de Lei n. 6.359/2013, cit.
} 
sais de flúor como resíduo. Esse fato ocorre com inúmeros produtos utilizados na alimentação infantil, como achocolatados, cereais matinais e vários tipos de bolachas, nos quais têm-se encontrado teores de flúor bem acima dos limites considerados aceitáveis para a saúde humana. O mesmo ocorre, é claro, com os alimentos preparados em casa, cozidos em água fluoretada ${ }^{14},{ }^{15}$.

\section{A fluoretação da água é economicamente injustificável}

Justificação dos PLs ns. 510/2003 e 6.359/2013:

Além dos riscos que a ingestão excessiva de flúor acarreta à saúde das pessoas, a fluoretação da água utilizada para abastecimento público é economicamente injustificável, pois apenas uma pequena parcela dela é ingerida. A maior parte é utilizada para higiene, lavagem de pisos e roupas, atividades de serviços e na pequena indústria difusa no meio urbano. É muito mais razoável e racional, sob todos os pontos de vista, que a administração do flúor como preventivo da cárie dentária seja feita de forma controlada, por profissionais habilitados, nas épocas certas, na forma e na quantidade cientificamente recomendadas ${ }^{16,}{ }^{17}$.

\section{0 mecanismo dos benefícios do flúor é principalmente tópico}

Justificação dos PL n. 6.359/2013:

Em suma, se o mecanismo dos benefícios do flúor é principalmente TÓPICO e NÃO SISTÊMICO, faz mais sentido, para aqueles que querem tomar os riscos, levar o flúor diretamente ao dente na forma de creme dental, tabletes ou pastilhas ${ }^{18}$. (Maiúsculas no original.)

\section{Resultados e discussão}

O PL n. 510/2003 e o PL n. 6.359/2013 são iniciativas parlamentares que pedem a revogação da Lei n. 6.050/1974. Isso corresponde a remover a base legal de uma política pública bem-sucedida há mais de 60 anos.

Não obstante a Justificação do PL n. 6.359/2013 ter sido publicada uma década após à do PL n. 510/2003, constatou-se que ambos os documentos têm

\footnotetext{
${ }^{14}$ BRASIL. Câmara dos Deputados. Projeto de Lei n. 503/2003, cit. ${ }^{15}$ BRASIL. Câmara dos Deputados. Projeto de Lei n. 6.359/2013, cit.

${ }^{16}$ BRASIL. Câmara dos Deputados. Projeto de Lei n. 503/2003, cit.

${ }^{17}$ BRASIL. Câmara dos Deputados. Projeto de Lei n. 6.359/2013, cit.

${ }^{18}$ Id. Ibid.
} 
praticamente o mesmo conteúdo e a mesma redação, exceto pela inclusão de um parágrafo no PL n. 6.359/2013 que faz referência ao mecanismo tópico de ação do flúor (Categoria V).

Os resultados são discutidos seguindo-se a ordem das categorias elencadas na seção do Método.

\section{Categoria I - A fluoretação da água surgiu como uma promessa de prevenir a cárie, mas é fruto de um equívoco científico}

Com base em conhecimentos científicos consistentes, corroborados por criteriosos processos de revisão sistemática - como o da University of York, da Inglaterra, e o da Cochrane Collaboration, para mencionar apenas dois desses centros -, pode-se afirmar que a fluoretação da água não é um equívoco científico. Dentre outros, esses centros mundiais de revisão sistemática sobre a produção científica em escala planetária confirmam as bases científicas da fluoretação da água. Uma das análises realizadas em um desses centros (University of York) é o estudo Systematic Review of Water Fluoridation, publicado no renomado periódico científico British Medical Journal, que consolidou essas bases e gerou evidência científica não questionada até o presente, em conformidade com o rigor exigido nos dias atuais ${ }^{19}$.

Os dois PLs também trazem a afirmação (ipsis litteris) de que a prevenção da cárie dentária foi o pretexto para se iniciar a adição de cloro na água destinada ao consumo humano. Contudo, jamais se cogitou, em qualquer país, adicionar cloro à água com o intuito de prevenir a cárie ${ }^{20}$. A cloração da água tem outra finalidade, igualmente importante em saúde pública, mas sem relação com cárie nem com fluoretos. A confusão entre fluoretação e cloração da água é frequente e predomina no senso comum ${ }^{21}$.

Com relação à origem da fluoretação da água, os PLs fazem referência ao final do século XIX, "quando foi observada a baixíssima incidência de cáries em populações de localidades britânicas onde a água continha, naturalmente, flúor”. Trata-se de informação incorreta, pois a fluoretação da água, como uma tecnologia de saúde pública, foi criada e desenvolvida no século XX nos Estados Unidos.

\footnotetext{
${ }^{19}$ MCDONAGH, Marian et al. A systematic review of public water fluoridation. New York: The University of York NHS, Centre for Review and Dissemination, 2000. Report 18. Disponivel em: <http://http://www.nhs.uk/ conditions/fluoride/documents/crdreport18.pdf> Acesso em: 30 set. 2009.

${ }^{20}$ CONSELHO REGIONAL DE ODONTOLOGIA DE SÃO PAULO. Ofício Pres. 002569/2014, cit.

${ }^{21}$ FERREIRA, Regina Glaucia Lucena Aguiar; BÓGUS, Claudia Maria; MARQUES, Regina Auxiliadora Amorim; MENEZES, Léa Maria Bezerra de; NARVAI, Paulo Capel. Fluoretação das águas de abastecimento público no Brasil: o olhar de lideranças de saúde. Cad. Saude Publica, Rio de Janeiro, v. 30, n. 9, p. 18841890, 2014. Disponível em: <http://www.scielo.br/pdf/csp/v30n9/0102-311X-csp-30-9-1884.pdf>. http://dx.doi.org/10.1590/0102-311X00165313.
} 
Tal tecnologia foi e ainda é bastante abordada em diversos artigos de relevância científica $^{22,23}$.

Segundo os documentos, "a adição de flúor à água utilizada para consumo humano passou, a partir do final da década de 1960, a ser considerada como uma verdadeira panaceia, que iria livrar as pessoas das cáries dentárias".

Esta é uma afirmação indevida. Não há registro, na literatura científica sobre fluoretação, de qualquer menção ao termo "panaceia” nem de alguma conotação nesse sentido. Ao contrário, há reconhecimento amplo e aceitação universal de que a cárie é uma doença multifatorial e de que, portanto, são necessárias ações articuladas de várias ordens para que a prevenção seja bem-sucedida. Conforme se pode constatar na literatura científica sobre o assunto, fluoretos não são e não devem ser vistos como antídotos contra cárie ${ }^{24}$.

Com relação à afirmação de que "Campanhas foram promovidas e programas instituídos, inclusive pela Organização Mundial da Saúde e pelo nosso Ministério da Saúde", trata-se de afirmação correta, pois essa tecnologia encontra-se entre as estratégias da Organização Mundial da Saúde (OMS) para melhorar a saúde bucal no século $\mathrm{XXI}^{25}$. Além disso, considera-se positivo que o Ministério da Saúde brasileiro oriente sua política nessa área em consonância com a recomendação da OMS e com a legislação brasileira sobre o tema.

\section{Categoria II - A fluoretação da água de abastecimento acarreta mais malefícios à saúde do que benefícios}

Entre os argumentos utilizados nas justificações dos dois PLs, encontra-se a afirmação de que,

a partir de estudos científicos aprofundados e de inúmeros fatos verificados entre as populações que consomem água fluoretada, constatou-se que, ao contrário do que se supunha, a fluoretação provoca muito mais males que benefícios à saúde pública, ao promover a ingestão excessiva e indiscriminada de flúor.

\footnotetext{
${ }^{22}$ DEAN, Henry Trendley. Endemic fluorosis and its relation to dental caries. Public Health Reports, v. 53, n. 33, p. 1443-1498, 1938.

${ }^{23}$ NARVAI, Paulo Capel. Cárie dentária e flúor: uma relação do século XX. Cienc. Saúde Coletiva, Rio de Janeiro, v. 5, n. 2, p. 381-392. 2000. Disponível em <http://www.scielo.br/pdf/csc/v5n2/7102.pdf>. http://dx.doi. org/10.1590/S1413-81232000000200011.

${ }^{24}$ BALDANI, Márcia Helena; NARVAI, Paulo Capel; ANTUNES, José Leopoldo Ferreira. Cárie dentária e condições sócio-econômicas no Estado do Paraná, Brasil, 1996. Cad. Saude Publica, Rio de Janeiro, v. 18. n. 3, p. 755-763, 2001. Disponível em: <http://www.scielo.br/pdf/csp/v18n3/9303.pdf>. http://dx.doi. org/10.1590/S0102-311X2002000300019.

${ }^{25}$ PETERSEN, Poul Erik; WORLD HEALTH ORGANIZATION - WHO. The World Oral Health Report 2003. Continuous improvement of oral health in the 21st century - the approach of the WHO Global Oral Health Programme. Disponível em: <http://www.who.int/oral_health/media/en/orh_report03_en.pdf>. Acesso em: 10 jan. 2016.
} 
Considera-se estapafúrdia tal afirmação, haja vista não possuir qualquer conexão com a literatura científica sobre o tema. Não há, nessa literatura, um artigo sequer que tenha sustentado a afirmação de que "a fluoretação provoca muito mais males que benefícios à saúde pública”. Não é possível identificar a origem ou a suposta base científica dessa afirmação despropositada, mas é possível encontrar sua contraposição na literatura científica ${ }^{26,27}$.

Ainda segundo as justificações dos dois PLs, "a ingestão elevada dessa substância provoca fluorose, doença óssea que se caracteriza pelo aparecimento de manchas e estrias escuras nos dentes, e, além de afetar a estética, torna os dentes porosos e quebradiços".

Tal informação é igualmente incorreta. A fluorose, esquelética ou dentária, é conhecida desde muito antes da adoção da fluoretação da água. Aliás, foi com base em estudos sobre esse problema endêmico em algumas regiões do mundo, onde há escassez de água e cujas populações não têm alternativas, que se desenvolveram os conhecimentos atuais sobre fluoretos, sua associação com prevenção da cárie dentária e a fluoretação da água como medida preventiva da cárie ${ }^{28}$.

Os autores dos dois PLs referem-se a um tipo da anomalia de formação, que é a fluorose severa, ou a alguns casos de fluorose moderada. Contudo, a fluoretação da água nada tem a ver com fluorose severa, cuja forma ocorre apenas em populações expostas a níveis muito elevados de flúor naturalmente existentes nas águas utilizadas para consumo humano. A fluoretação da água não está associada estatisticamente com essa forma de fluorose, de modo relevante. Estão disponíveis na literatura científica mundial vários artigos científicos cujas conclusões convergem para o reconhecimento de que fluoretar a água não produz fluorose dentária clinicamente significativa - alguns deles de autoria dos Centers for Disease Control and Prevention ${ }^{29}$, a agência de saúde pública do governo dos Estados Unidos.

Ambos os PLs referem-se à fluorose como "a principal doença causada pela ingestão excessiva de flúor". Esta afirmação é correta, mas a fluoretação da água não prevê, nem propõe, que haja ingestão excessiva de fluoretos. Trata-se, justamente, do oposto disso. Trata-se de controlar os teores de flúor em águas de consumo humano, controle este que, segundo a vigilância sanitária, deve se estender a quaisquer águas, inclusive as engarrafadas (ou ditas minerais).

\footnotetext{
${ }^{26}$ GRIFFIN, Susan O. et al. Effectiveness of fluoride in preventing caries in adults. Journal of Dental Research, v. 86, n. 5, p. 410-415, May 2007. 10.1177/154405910708600504.

${ }^{27}$ RUGG-GUNN, Andrew John; DO Loc. Effectiveness of water fluoridation in caries preventions. Community Dent Oral Epidemiol, v. 40, n. 2, p. 55-64, 2012. 10.1111/j.1600-0528.2012.00721.

${ }^{28}$ CLARK, D Cristopher; BERKOWITZ, Jonathan. The influence of various fluoride exposures on the prevalence of esthetic problems resulting from dental fluorosis. J Public Health Dent, v. 57, n. 3, p. 144-149, 1997.

${ }^{29}$ CENTERS FOR DISEASES CONTROL AND PREVENTION. Achievements in public health, 1900-1999. Fluoridation of drinking water to prevent dental caries. MMWR Morbidity and Mortality Weekly Report, v. 48, n. 41, p. 933940, Oct. 1999. Disponível em: <https://www.cdc.gov/mmwr/preview/mmwrhtml/mm4841a1.htm>.
} 
Além dos problemas dentários supracitados, a perda de cálcio dos ossos e o envelhecimento precoce das pessoas também foram citados nas Justificações, afirmando-se que "tais efeitos" teriam sido "amplamente comprovados no Estado de Rajasthan, na Índia, onde águas de poços utilizados para o abastecimento de vários povoados contêm elevados teores de flúor". Acrescenta-se a informação de que "nas populações desses povoados, segundo o Centro de Pesquisa sobre Fluorose e Desenvolvimento Rural de Nova Délhi [sic], veem-se claramente os efeitos nocivos do flúor, consistindo a fluorose em um sério problema de saúde pública”.

Tais afirmações são corretas e corroboradas por estudos científicos bem conduzidos na Índia ${ }^{30}$. Naquele país, contudo, há vastas regiões em que os teores de fluoreto naturalmente existentes em águas são superiores a 10 partes por milhão $(\mathrm{ppm})^{31,32}$. Há países na África (Tunísia, Quênia, dentre outros) em que ocorre fenômeno simular ${ }^{33}$. O mesmo se dá na Indonésia ${ }^{34}$, no Sri Lanka ${ }^{35} \mathrm{e}$ em áreas do México, da Argentina ${ }^{17}$ e dos Estados Unidos ${ }^{36}$, dentre outros países ${ }^{37}$. Fenômeno similar, embora com teores menores de fluoreto, ocorre em alguns municípios brasileiros, como Itambaracá, no Paraná ${ }^{38}$, Pereiras, em São Paulo ${ }^{39}$, e alguns municípios da Paraíba, dentre os quais Princesa Isabe ${ }^{40}$. São problemas decorrentes da presença, natural, de elevados teores de fluoreto em águas que a população utiliza para consumo e demais necessidades da vida diária. Nesses contextos, essas águas, mesmo com

${ }^{30}$ CHANDRASHEKAR, Janakiram; THANKAPPAN, Kavumpurathu R.; SUNDARAM, K. R. Severe dental fluorosis and jowar consumption in Karnataka, India. Community Dent Oral Epidemiol., v. 38, n. 6, p. 559-567, 2010. 10.1111/j.1600-0528.2010.00564.x.

${ }^{31}$ HANDA, B. K. Geochemistry and genesis of fluoride-containing ground waters in India. Groundwater, v. 13, n. 3, p. 275-281, May 1975. 0.1111/j.1745-6584.1975.tb03086.x.

${ }^{32}$ WORLD HEALTH ORGANIZATION - WHO. Fluorine and fluorides. Geneve: WHO, 1984 (Environmental health criteria; 36). Disponível em: <http:// http://apps.who.int/iris/handle/10665/37288>. Acesso em: 12 jan. 2016.

${ }^{33}$ WILLIAMSON, Mark M. Endemic dental fluorosis in Kenya: a preliminary report. East African Medical Journal, v.30, n. 6, p. 217-233, Jun. 1953.

${ }^{34}$ BUDIPRAMANA, Els; HAPSORO, Adi; IRMAWATI, Suhariadji; KUNTARI, Satiti. Dental fluorosis and caries prevalence in the fluorosis endemic area of Asembagus, Indonesia. International Journal of Paediatric Dentistry. v. 12, n. 6, p. 415-422, Nov. 2002.

${ }^{35}$ DISSANAYAKE, Chandra Bandara. The fluoride problem in the ground water of Sri Lanka - environmental management and health. International Journal of Environmental Studies, v. 38, n. 2-3, p. 137-155, 1991. Disponível em: <https://doi.org/10.1080/00207239108710658>.

${ }^{36}$ DEAN, Henry Trendley. op. cit.

${ }^{37}$ AMINI, Manouchehr; MUELLER, Kim; ABBASPOUR, Karim; ROSENBERG, Thomas; AFYUNI, Majid; MØLLER, Klaus; SARR, Mamadou; JOHNSON, C. Annette. Statistical Modeling of Global Geogenic Fluoride Contamination in Groundwaters Environ. Sci. Technol, v. 42, n. 10, p. 3662-3668, 2008. Disponível em: <https://pubs.acs.org/doi/pdf/10.1021/es071958y>. 10.1021/es071958y.

${ }^{38}$ FROSSARD, Wanda Terezinha Garbelini. Ocorrência de opacidade difusa em molares decíduos como fator preditivo no diagnóstico de fluorose dentaria em dentes permanentes. 2003. Tese (Doutorado) Universidade Estadual Paulista - UNESP, Faculdade de Odontologia de Araçatuba, 2003.

${ }^{39}$ SOARES, Marta Desire do Carmo Moreira; GASPAR, Márcia Regina; PEREIRA, Antonio Carlos; MOREIRA, Ben Hur Wey. Localidades com diferentes concentrações de flúor nas águas de consumo e sua relação com a prevalência de fluorose. Odontol Mod. v. 22, n. 4, p.18-21, out./dez. 1995.

${ }^{40}$ FORTE, Franklin Delano Soares; FREITAS, Claudia Helena Soares Morais; SAMPAIO, Fábio Correia; JARDIM, Maria Carmem Araújo Melo. Fluorose dentária em crianças de Princesa Isabel, Paraíba. Pesqui Odontol Bras. v. 15, n. 2, p. 87-90, abr./jun. 2001. Disponível em: <http://www.scielo.br/pdf/pob/v15n2/ a02v15n2.pdf>. http://dx.doi.org/10.1590/S1517-74912001000200002. 
excesso de flúor, são as únicas disponíveis, não sendo viável impedir as populações de as utilizarem. Esses fenômenos dramáticos, entretanto, nada têm a ver com a tecnologia de saúde pública conhecida como "fluoretação da água", tal como utilizada no Brasil, nos Estados Unidos, na Austrália e em outros países. Documentos oficiais da Organização Mundial da Saúde corroboram essa afirmação ${ }^{41}$.

Em suas justificações, os PLs afirmam, ainda, que,

nos Estados Unidos, o Dr. William Marcus, toxicologista da Environmental Protection Agency (EPA) - a agência ambiental federal daquele país -, detectou estreita correlação entre o crescimento dos casos de um tipo de câncer ósseo, o osteossarcoma, e a ingestão de flúor. Outro estudo, realizado no estado de Nova Jersey, comparou a incidência desse tipo de câncer em vários municípios, concluindo que era maior onde era feita a fluoretação. Esse tipo de câncer atinge, principalmente, rapazes com menos de vinte anos de idade.

Não há correlação “estreita” ( $\mathrm{sic}$ ), nem positiva nem negativa, nem forte nem fraca, entre fluoretos presentes em águas, em teores preconizados para prevenir cárie no Brasil ${ }^{42}$ e neoplasias, conforme aventado ${ }^{43}$. Várias revisões sistemáticas sobre o tema indicam a inexistência de associação entre uma coisa e outra ${ }^{44}$.

Young et al. ${ }^{45}$ também constataram a inexistência de efeitos nocivos à saúde, ao analisarem possível associação entre fluoretação e fraturas de quadril, osteossarcoma ou outros tipos de câncer. Por outro lado, houve evidência de associação negativa entre fluoretação e todas as causas de mortalidade (1,3\% inferior; $95 \%$ CI-2,5\%, - 0,1\%; P = 0,04). Os autores observaram, ainda, uma associação estatisticamente significante entre residir em áreas com água fluoretada e menores taxas de cárie dentária na infância.

\section{Categoria III - Existe imprecisão quanto à dosagem do flúor}

"Um dos problemas mais sérios da fluoretação da água para abastecimento público é a imprecisão quanto à dosagem dessa substância”. Ao utilizarem o termo "dosagem", expresso neste trecho dos dois PL, seus autores cometem um equívoco,

\footnotetext{
${ }^{41}$ PETERSEN, Poul Erik; LENNON, Michael A. Effective use of fluorides for the prevention of dental caries in the 21st century: the WHO approach. Community Dentistry and Oral Epidemiology, v. 32, n. 5, p. 319-321, Oct. 2004.

${ }^{42}$ BRASIL. Ministério da Saúde. Portaria n. 518, de 25 de março de 2004, cit.

${ }^{43}$ BRASIL. Câmara dos Deputados. Projeto de Lei n. 510/2003, cit.

${ }^{44}$ CENTERS FOR DISEASES CONTROL AND PREVENTION. Achievements in public health, 1900-1999. Fluoridation of drinking water to prevent dental caries, cit., p. 933-940.

${ }^{45}$ YOUNG, Nicholas; NEWTON, John; MORRIS, John; MORRIS, Joan; LANGFORD, John; ILOYA, Jonathan; EDWARDS, Diane; MAKHANI, Semina. Community water fluoridation and health outcomes in England: a cross-sectional study. Community Dent Oral Epidemiol, v. 43, n. 6, p. 550-559. 2015. 10.1111/cdoe.12180.
} 
haja vista não se tratar de "dosagem", posto que a presença de fluoretos em águas é ocorrência normal, algo comum. Fluoretar a água é uma tecnologia de saúde pública que consiste justamente em ajustar e controlar esses teores naturalmente existentes em águas utilizadas para consumo humano. Assim, não há que se falar em "dosagem", termo cuja conotação indica se tratar de medicação. Há situações em que, por desconhecimento, fala-se inclusive em "medicação em massa", que estaria a "intoxicar" populações expostas. Ambas as conotações - a de medicação "em massa" e a de "intoxicação" - nada têm a ver com a fluoretação tal como preconizada por organismos nacionais e internacionais de saúde pública. A propósito, seria mesmo néscio que instituições incumbidas de proteger a saúde da população a intoxicassem deliberadamente, utilizando em massa produtos nocivos à saúde por meio de ações sem o devido amparo em conhecimentos científicos consistentes.

Quanto à variabilidade na concentração dos fluoretos na água, referida pelos documentos (PLs), as variações observadas quando é feita a fluoretação das águas são oscilações perfeitamente compatíveis com a tecnologia. Processos corriqueiros de controle operacional, em estações de tratamento de água, são suficientes para manter tais oscilações dentro de limites, fazendo com que não tenham significado clínico relevante.

Os estudos referidos e atribuídos à pesquisadora Marília Buzalaf ${ }^{46}$ indicam que as variações no teor dos fluoretos não são "enormes" (termo usado nas justificações), e a conclusão da referida pesquisadora é que a população bauruense é beneficiada pela fluoretação da água, e não o contrário, sendo a medida executada de acordo com o preconizado pelos estudiosos do assunto. Nada há de errado, atualmente, com a fluoretação em Bauru, segundo os estudos lá realizados, sendo necessário apenas seguir fazendo vigilância sanitária da medida, conforme recomendam o Ministério da Saúde e pesquisadores brasileiros e internacionais ${ }^{47}$. Estudo do qual a referida pesquisadora é coautora analisou a prevalência de cárie em "escolares de 12 anos de idade, em Bauru, São Paulo, nos anos de 1976, 1984, 1990 e 1995. Participaram dos levantamentos epidemiológicos 261 indivíduos em 1976, 321 em 1984, 253 em 1990 e 377 em 1995". Concluiu-se que "houve redução de cárie dentária da ordem de 58,24 por cento no período, passando o CPOD de 9,89 em 1976 para 4,13 em 1995. O percentual de crianças livres de cárie dentária evoluiu de 0,40 por cento em 1976 para 16,70 por cento em 1995"; "houve também importante mudança em termos de redução de indivíduos com dentes acometidos de cárie dentária”. Os escolares

\footnotetext{
${ }^{46}$ BUZALAF, Marília Afonso Rabelo; GRANJEIRO, José Mauro; DAMANTE, Carla Andreotti; ORNELAS, Flávia. Fluctuations in public water fluoride level in Bauru, Brazil. Journal of Public Health Dentistry. v. 62, n. 3, p. 173-176, 2002.

${ }^{47}$ CENTRO COLABORADOR DO MINISTÉRIO DA SAÚDE EM VIGILÂNCIA DA SAÚDE BUCAL. Consenso técnico sobre classificação de águas de abastecimento público segundo o teor de flúor. São Paulo: Faculdade de Saúde Pública da Universidade de São Paulo; 2011. Disponível em: <http://www.cecol. fsp.usp.br/dcms/uploads/arquivos/1398177715_CECOL-USP-ClassificacaoAguasSegundoTeorFluorDocumentoConsensoTecnico-2011.pdf>. Acesso em: 12 jan. 2016.
} 
que apresentavam seis dentes ou mais atingidos pela doença eram 87,0 por cento em 1976; essa porcentagem declinou "para 29,8 por cento em 1995, reduzindo-se, então, drasticamente as necessidades de tratamento dentário" 48 .

Com relação à alegação de que "as concentrações muito baixas fazem a fluoretação ineficaz, enquanto que aquelas muito elevadas sujeitam os consumidores da água à ação tóxica do flúor", é uma afirmação correta. Entretanto, a fluoretação da água em conformidade com a regulamentação brasileira e devidamente monitorada serve justamente para que não haja "concentrações muito baixas" de fluoretos nas águas, situação que predomina amplamente nas águas do território brasileiro, requerendo, portanto, que sejam adicionados fluoretos até que atinjam o teor ideal. Quanto às "concentrações muito elevadas", nada têm a ver com a fluoretação das águas; tais concentrações muito elevadas são encontradas em algumas partes do território brasileiro, bem como de outros países, e há unanimidade entre os cientistas e sanitaristas de que tais águas não devem ser utilizadas para consumo humano. É incompreensível, portanto, a associação de ideias feitas nas justificações dos PLs, uma vez que a tecnologia da fluoretação da água requer o controle sobre os teores de fluoretos. Logo, a tecnologia faz justamente o oposto do que é, erroneamente, atribuído a ela.

Água adequadamente fluoretada não é vista como problema quando utilizada no preparo caseiro de alimentos e na indústria alimentícia, e sim como solução para a prevenção e o controle da cárie dentária em populações, sobretudo no cenário de desigualdades observado no Brasil. O uso de tais águas no preparo doméstico e industrial de alimentos é compatível com a tecnologia e não implica qualquer dificuldade a sua eficácia e efetividade.

A afirmação de que "a maior parte da água empregada no cozimento de alimentos e em processos industriais é evaporada, deixando os sais de flúor como resíduo" não é procedente, pois, do ponto de vista bioquímico, não é isso o que ocorre, não tendo significado clínico ou fisiológico relevante. A afirmação é genérica e descontextualizada, não sendo pertinente à temática posta pelos PLs.

Os documentos ainda alegam que, em "inúmeros produtos utilizados na alimentação infantil, como achocolatados, cereais matinais e vários tipos de bolachas, têm-se encontrado teores de flúor bem acima dos limites considerados aceitáveis para a saúde humana”. Ora, a tecnologia de fluoretação da água é compatível com cenários de exposição a múltiplas fontes de fluoretos. Cogitar interromper a fluoretação e revogar a lei brasileira em decorrência das características do processamento de alimentos não encontra justificativa clínica ou epidemiológica.

\footnotetext{
${ }^{48}$ BASTOS, José Roberto; BUZALAF, Marília Rabelo; LEVY, Flávia Mauad; RIBEIRO, Thiago Turri; MAZZONE, Flávio H. R. Concentração de flúor em água mineral engarrafada e de fontes naturais das cidades de Lindóia, Águas de Lindóia e Serra Negra, Brasil. Revista da Faculdade de Odontologia. Universidade de Passo Fundo, Rio Grande do Sul, v. 6, n. 1, p. 15-19, 2001.
} 


\section{Categoria IV - A fluoretação da água é economicamente inviável}

A afirmação de que "a fluoretação da água utilizada para abastecimento público é economicamente injustificável, pois apenas uma pequena parcela dela é ingerida" é impertinente. É inadequada a associação de ideias entre "ingestão excessiva de flúor" e "fluoretação da água", uma vez que a tecnologia de fluoretação da água corresponde ao oposto. A fluoretação da água pressupõe controle dos teores de fluoreto nas águas de consumo humano, agregando fluoretos quando a água é hipofluorada e removendo fluoretos quando a água é hiperfluorada (embora a remoção encontre barreira nos custos e tecnologias para desfluoretar a água). Sobre custo-benefício da fluoretação da água, pode-se afirmar que é a medida de melhor custo-efetividade para prevenção da cárie dentre todas as disponíveis. O custo para beneficiar uma pessoa ao longo de toda a sua vida equivale à metade do custo de uma restauração dentária. Pesquisa feita no Brasil sobre custos da fluoretação indicou que manter o benefício por período de aproximadamente cinco anos custou menos do que $\mathrm{R} \$ 1,00$ por pessoa ${ }^{49}$.

Quanto à alegação de que a maior parte da água é utilizada para "higiene, lavagem de pisos e roupas, atividades de serviços e na pequena indústria difusa no meio urbano", cabe assinalar que os custos da fluoretação - inclusive nas análises de custo-efetividade da medida - levam em conta todos os usos da água de abastecimento público. Ainda assim, a tecnologia não encontra paralelo em nenhuma outra medida preventiva da cárie, sendo a de melhor custo-benefício.

Apesar de os autores dos PL julgarem "muito mais razoável e racional, sob todos os pontos de vista, que a administração do flúor como preventivo da cárie dentária seja feita de forma controlada, por profissionais habilitados, nas épocas certas, na forma e na quantidade cientificamente recomendadas", eles não justificam, com argumentos válidos, essa afirmação. É oportuno reiterar que não há incompatibilidade entre diferentes modos de utilizar fluoretos para prevenção da cárie. Assim, o que não é racional é pretender opor um modo a outro. O que se deve assegurar é que as técnicas denominadas de "associação de métodos" tenham amparo na literatura científica. Ao invés de fazer apelos retóricos e não fundamentados à razoabilidade, deve-se buscar que a legislação brasileira sobre o assunto tenha amparo em conhecimentos científicos sólidos, e não em crendices ou no senso comum. As autoridades sanitárias e os coordenadores de saúde bucal conhecem essas técnicas de associação de métodos e devem ser respeitados em suas competências profissionais.

\footnotetext{
${ }^{49}$ FRIAS, Antonio Carlos; NARVAI Paulo Capel; ARAÚJO Maria Ercilia; ZILBOVICIUS Celso; ANTUNES José Leopoldo Ferreira. Custo da fluoretação das águas de abastecimento público, estudo de caso - Município de São Paulo, Brasil, período de 1985-2003. Cad. Saude Publica, Rio de Janeiro, v. 22, n. 6, p. 1237-1246, 2006. Disponivel em: <http://www.scielo.br/pdf/csp/v22n6/13.pdf>. http://dx.doi.org/10.1590/S0102$311 \times 2006000600013$.
} 


\section{Categoria V-O mecanismo dos benefícios do flúor é principalmente tópico}

Importante ressaltar que esta categoria de análise surgiu exclusivamente das Justificações do PL n. 6.359/2013, não tendo seu antecessor (PL n. 510/2003) feito qualquer menção ao assunto. O parágrafo a seguir é, pois, a única diferença de conteúdo entre o PL n. 510/2003 e o PL n. 6.359/2013:

Em suma, se o mecanismo dos benefícios do flúor é principalmente TÓPICO e NÃO SISTÊMICO, faz mais sentido, para aqueles que querem tomar os riscos, levar o flúor diretamente ao dente na forma de creme dental, tabletes ou pastilhas. (Maiúsculas no original.)

A dedução não procede com base na lógica formal. Ao argumentar, o autor da Justificação confunde de maneira enfática (representada por letras maiúsculas) "modo de uso" com "mecanismo de ação", os quais são aspectos completamente distintos. O fato de o mecanismo de ação ser local não equivale a utilizar veículos locais como modo de uso. Sanitaristas e bioquímicos não recomendam utilizar fluoretos sob a forma de comprimidos, tabletes ou pastilhas. Fluoretos podem e devem ser usados de modo responsável e, sempre, sob controle profissional. Nesses aspectos, lamentavelmente não há como argumentar sem ser "pedagógico" - e não é este o propósito deste artigo, embora caiba a recomendação de que parlamentares interessados no assunto estudem a matéria antes de proporem alteração na legislação brasileira.

Por oportuno, uma vez que não havia esse parágrafo em 2003, deduz-se que dez anos depois a única novidade foi que o emprego dos vocábulos "TÓPICO" e "NÃO SISTÊMICO" pretende dar lições (equivocadas) sobre modos de uso de fluoretos - lembrando que, no contexto da linguagem escrita, usar letras maiúsculas equivale, no plano simbólico, ao "falar alto" ou ao "gritar" da linguagem oral. Em vez disso, teria sido melhor aprimorar os argumentos.

As justificações dos dois PLs propõem, em seus trechos finais, a revogação da Lei n. 6.050, de 24 de maio de 1974, conforme segue.

PL n. 510/2003:

Estas são, em resumo, as razões que nos levaram à presente iniciativa, que propõe a revogação da Lei n. 6.050, de 24 de maio de 1974, para cuja tramitação, aperfeiçoamento e aprovação contamos com o apoio dos ilustres membros do Congresso Nacional.

PL n. 6.359/2013:

Estas razões nos levaram à presente iniciativa, que propõe a revogação da Lei n. 6.050, de 24 de maio de 1974. Cabe observar que já fora apresentada a esta Casa pelo PL n. 95, de 2007, arquivado, de autoria do Deputado Carlos Souza. Pela sua importância, desejo 
novo estudo e deliberação pelo Congresso Nacional sobre o tema, para cuja tramitação, aperfeiçoamento e aprovação, contamos com o apoio dos ilustres membros desta Casa.

É oportuna a observação de que outros projetos de lei foram apresentados à Câmara, e também ao Senado, nos últimos anos. Ao seu tempo, cada um desses PLs teve suas justificações devidamente contestadas por entidades de saúde pública, de odontologia e de saneamento e também por instituições públicas, restando claro que não há sustentação científica para essas proposições e que revogar a Lei n. 6.050/1974 seria um enorme retrocesso, com gravíssimas consequências para a saúde bucal da população brasileira, que vem se beneficiando muito com a fluoretação das águas.

A esse respeito, recomenda-se que interessados no assunto recorram à literatura científica, cujas conclusões não deixam margem à dúvida sobre quão nocivas são iniciativas parlamentares que visam à revogação da lei brasileira que ampara a fluoretação $0^{50}, 51$.

Nesse sentido, é altamente recomendável que, antes de apresentar projetos de lei, os proponentes estudem o assunto a que se referem tais PLs. Em situações como a mencionada na presente justificação - pedindo observância ao fato de que "já fora apresentada a esta Casa pelo PL n. 95, de 2007, arquivado, de autoria do Deputado Carlos Souza" -, uma vez mais avulta a necessidade de que os proponentes estudem a matéria. Isso teria evitado a repetição de argumentos inconsistentes, anticientíficos e, sobretudo, sem base na realidade epidemiológica e sanitária brasileira. Acresce que, no caso presente, até mesmo a referência ao PL do deputado Carlos Souza está errada, uma vez que não se trata de um, mas de dois projetos de lei apresentados à Câmara pelo mesmo parlamentar. Impõe-se também informar que o PL n. 95/2007 é mera reedição do PL n. 510, do mesmo deputado amazonense e que fora apresentado originalmente em 2003. Em ambos, há o mesmo erro, agora repetido neste PL n. 6359, de 2013: a informação, estapafúrdia, de que cloro é adicionado às águas para prevenir cárie dentária.

Essa aparente falta de atenção e cuidado dos parlamentares e de seus assessores técnicos na proposição de leis que tratam de assuntos tão sérios sobre saúde em nosso país impõe a necessidade de uma espécie de "vigilância parlamentar", pois, ao que tudo indica, eles não se deram nem mesmo ao trabalho de mudar o texto no novo PL, mesmo tendo acesso ao parecer do Governo Federal que rebateu ponto por ponto os argumentos expostos. Ademais, proposições tão mal fundamentadas apenas acarretam custos processuais inúteis, cuja consequência mais relevante é onerar o orçamento da República.

\footnotetext{
${ }^{50}$ NARVAI, Paulo Capel; FRAZÃO, Paulo; RONCALLI, Angelo Giuseppe, ANTUNES, José Leopoldo Ferreira. Cárie dentária no Brasil: declínio, polarização, iniquidade e exclusão social. Pan Am J Public Health, v. 19, n. 6, p. 385-393, 2006. Disponível em: <https://scielosp.org/pdf/rpsp/2006.v19n6/385-393>.

${ }^{51}$ ANTUNES, José Leopoldo Ferreira; NARVAI, Paulo Capel. Políticas de saúde bucal no Brasil e seu impacto sobre as desigualdades em saúde. Revista de Saúde Pública, São Paulo, v. 44, p. 360-365, 2010. Disponível em: <http:// www.scielo.br/pdf/rsp/v44n2/C01239.pdf>. http://dx.doi.org/10.1590/S0034-89102010005000002.
} 


\section{Considerações Finais}

A fluoretação de águas de abastecimento tornou-se, ao longo do século $\mathrm{XX}$, uma das ações de maior impacto na prevenção da cárie dentária, e a Lei n. 6.050/1974 tornou-se um referencial jurídico de suma importância para a implantação dessa medida em milhares de municípios do território nacional. Consequentemente, beneficiou milhões de brasileiros, ultrapassando as limitações de acesso a ações de prevenção individuais e à assistência odontológica. O questionamento sobre as razões e os interesses que motivam parlamentares brasileiros a apresentar Projetos de Lei que acarretam sérios prejuízos à saúde das populações, sem qualquer debate com a sociedade, deve ser objeto de atenção permanente por parte dos segmentos sociais comprometidos com essa questão. É importante ressaltar que eventuais deficiências dos PLs não resultam das dificuldades de assessoramento técnico científico, mas de posições adotadas pelos proponentes dos respectivos PLs as quais derivam do contexto político e cujas motivações implicam a ocultação dos interesses subjacentes à iniciativa parlamentar. Ressalta-se, portanto, que tal ocultação é inerente ao modo como os PLs são gerados e tramitam no Parlamento. A suspensão dessa importante medida sanitária, interrompendo uma política de mais de meio século, seria um ato de injustiça para com a sociedade brasileira, e esta deve estar atenta às justificativas de projetos que visam à revogação da lei que a instituiu no país. Analisar e contra-argumentar projetos de lei, como buscamos fazer neste estudo, constitui um dever elementar dos pesquisadores do assunto, com vistas a reforçar os avanços conquistados pela sociedade brasileira em prol de sua saúde.

\section{Referências}

AMINI, Manouchehr; MUELLER, Kim; ABBASPOUR, Karim; ROSENBERG, Thomas; AFYUNI, Majid; MØLLER, Klaus; SARR, Mamadou; JOHNSON, C. Annette. Statistical Modeling of Global Geogenic Fluoride Contamination in Groundwaters Environ. Sci. Technol, v. 42, n. 10, p. 3662-3668, 2008. Disponível em: <https://pubs.acs.org/doi/pdf/10.1021/ es071958y>. 10.1021/es071958y.

ANTUNES, José Leopoldo Ferreira; NARVAI, Paulo Capel. Políticas de saúde bucal no Brasil e seu impacto sobre as desigualdades em saúde. Revista de Saúde Pública, São Paulo, v. 44, p. 360-365, 2010. Disponível em: <http://www.scielo.br/pdf/rsp/v44n2/CO1239.pdf>. http://dx.doi.org/10.1590/S0034-89102010005000002.

BALDANI, Márcia Helena; NARVAI, Paulo Capel; ANTUNES, José Leopoldo Ferreira. Cárie dentária e condições sócio-econômicas no Estado do Paraná, Brasil, 1996. Cad. Saude Publica, Rio de Janeiro, v. 18. n. 3, p. 755-763, 2001. Disponível em: <http://www.scielo.br/pdf/csp/ v18n3/9303.pdf>. http://dx.doi.org/10.1590/S0102-311X2002000300019.

BARDIN, Laurence. Análise de conteúdo. Lisboa: Edições 70, LDA, 2009. 
BASTOS, José Roberto; BUZALAF, Marília Rabelo; LEVY, Flávia Mauad; RIBEIRO, Thiago Turri; MAZZONE, Flávio H. R. Concentração de flúor em água mineral engarrafada e de fontes naturais das cidades de Lindóia, Águas de Lindóia e Serra Negra, Brasil. Revista da Faculdade de Odontologia. Universidade de Passo Fundo, Rio Grande do Sul, v. 6, n. 1, p. 15-19, 2001.

BUDIPRAMANA, Els; HAPSORO, Adi; IRMAWATI, Suhariadji; KUNTARI, Satiti. Dental fluorosis and caries prevalence in the fluorosis endemic area of Asembagus, Indonesia. International Journal of Paediatric Dentistry. v. 12, n. 6, p. 415-422, Nov. 2002.

BUZALAF, Marília Afonso Rabelo; GRANJEIRO, José Mauro; DAMANTE, Carla Andreotti; ORNELAS, Flávia. Fluctuations in public water fluoride level in Bauru, Brazil. Journal of Public Health Dentistry. v. 62, n. 3, p. 173-176, 2002.

CENTERS FOR DISEASES CONTROL AND PREVENTION. Achievements in public health, 1900-1999. Fluoridation of drinking water to prevent dental caries. MMWR Morbidity and Mortality Weekly Report, v. 48, n. 41, p. 933-940, Oct. 1999. Disponível em: <https://www. cdc.gov/mmwr/preview/mmwrhtml/mm4841a1.htm>.

CENTRO COLABORADOR DO MINISTÉRIO DA SAÚDE EM VIGILÂNCIA DA SAÚDE BUCAL. Consenso técnico sobre classificação de águas de abastecimento público segundo o teor de flúor. São Paulo: Faculdade de Saúde Pública da Universidade de São Paulo; 2011. Disponível em: <http://www.cecol.fsp.usp.br/dcms/uploads/arquivos/1398177715_CECOL-USP-Classifica caoAguasSegundoTeorFluor-DocumentoConsensoTecnico-2011.pdf >. Acesso em: 12 jan. 2016.

CHANDRASHEKAR, Janakiram; THANKAPPAN, Kavumpurathu R.; SUNDARAM, K. R. Severe dental fluorosis and jowar consumption in Karnataka, India. Community Dent Oral Epidemiol., v. 38, n. 6, p. 559-567, 2010. 10.1111/j.1600-0528.2010.00564.x.

CLARK, D Cristopher; BERKOWITZ, Jonathan. The influence of various fluoride exposures on the prevalence of esthetic problems resulting from dental fluorosis. J Public Health Dent, v. 57, n. 3, p. 144-149, 1997.

CONSELHO REGIONAL DE ODONTOLOGIA DE SÃO PAULO. Ofício Pres. 002569/2014: Encaminha solicitação ao Deputado Federal Dr. Vicente Cândido da Silva, presidente da Comissão de Constituição e Justiça e de Cidadania. São Paulo, 2014.

DEAN, Henry Trendley. Endemic fluorosis and its relation to dental caries. Public Health Reports, v. 53, n. 33, p. 1443-1498, 1938.

DISSANAYAKE, Chandra Bandara. The fluoride problem in the ground water of Sri Lanka - environmental management and health. International Journal of Environmental Studies, v. 38, n. 2-3, p. 137-155, 1991. Disponível em: <https://doi.org/10.1080/00207239108710658>.

FERREIRA, Regina Glaucia Lucena Aguiar; BÓGUS, Claudia Maria; MARQUES, Regina Auxiliadora Amorim; MENEZES, Léa Maria Bezerra de; NARVAI, Paulo Capel. Fluoretação das águas de abastecimento público no Brasil: o olhar de lideranças de saúde. Cad. Saude Publica, Rio de Janeiro, v. 30, n. 9, p. 1884-1890, 2014. Disponível em: <http://www.scielo.br/pdf/csp/ v30n9/0102-311X-csp-30-9-1884.pdf>. http://dx.doi.org/10.1590/0102-311X00165313. 
FORTE, Franklin Delano Soares; FREITAS, Claudia Helena Soares Morais; SAMPAIO, Fábio Correia; JARDIM, Maria Carmem Araújo Melo. Fluorose dentária em crianças de Princesa Isabel, Paraíba. Pesqui Odontol Bras. v. 15, n. 2, p. 87-90, abr./ jun. 2001. Disponível em: <http://www.scielo.br/pdf/pob/v15n2/a02v15n2.pdf>. http://dx.doi.org/10.1590/S1517-74912001000200002.

FRIAS, Antonio Carlos; NARVAI Paulo Capel; ARAÚJO Maria Ercilia; ZILBOVICIUS Celso; ANTUNES José Leopoldo Ferreira. Custo da fluoretação das águas de abastecimento público, estudo de caso - Município de São Paulo, Brasil, período de 1985-2003. Cad. Saude Publica, Rio de Janeiro, v. 22, n. 6, p. 1237-1246, 2006. Disponível em: <http://www.scielo.br/pdf/csp/ v22n6/13.pdf>. http://dx.doi.org/10.1590/S0102-311X2006000600013.

FROSSARD, Wanda Terezinha Garbelini. Ocorrência de opacidade difusa em molares decíduos como fator preditivo no diagnóstico de fluorose dentaria em dentes permanentes. 2003. Tese (Doutorado) - Universidade Estadual Paulista - UNESP, Faculdade de Odontologia de Araçatuba, 2003.

GRIFFIN, Susan O. et al. Effectiveness of fluoride in preventing caries in adults. Journal of Dental Research, v. 86, n. 5, p. 410-415, May 2007. 10.1177/154405910708600504.

HANDA, B. K. Geochemistry and genesis of fluoride-containing ground waters in India. Groundwater, v. 13, n. 3, p. 275-281, May 1975. 0.1111/j.1745-6584.1975.tb03086.x.

MCDONAGH, Marian et al. A systematic review of public water fluoridation. New York: The University of York NHS, Centre for Review and Dissemination, 2000. Report 18. Disponível em: <http://http://www.nhs.uk/conditions/fluoride/documents/crdreport18.pdf> Acesso em: 30 set. 2009.

NARVAI, Paulo Capel. Cárie dentária e flúor: uma relação do século XX. Cienc. Saúde Coletiva, Rio de Janeiro, v. 5, n. 2, p. 381-392. 2000. Disponível em <http://www.scielo.br/pdf/csc/ v5n2/7102.pdf>. http://dx.doi.org/10.1590/S1413-81232000000200011.

NARVAI, Paulo Capel; FRAZÃO, Paulo; RONCALLI, Angelo Giuseppe, ANTUNES, José Leopoldo Ferreira. Cárie dentária no Brasil: declínio, polarização, iniquidade e exclusão social. Pan Am J Public Health, v. 19, n. 6, p. 385-393, 2006. Disponível em: <https://scielosp. org/pdf/rpsp/2006.v19n6/385-393>.

PETERSEN, Poul Erik; LENNON, Michael A. Effective use of fluorides for the prevention of dental caries in the 21st century: the WHO approach. Community Dentistry and Oral Epidemiology, v. 32, n. 5, p. 319-321, Oct. 2004.

PETERSEN, Poul Erik; WORLD HEALTH ORGANIZATION - WHO. The World Oral Health Report 2003. Continuous improvement of oral health in the 21st century - the approach of the WHO Global Oral Health Programme. Disponível em: <http://www.who.int/oral_health/ media/en/orh_report03_en.pdf>. Acesso em: 10 jan. 2016.

RUGG-GUNN, Andrew John; DO Loc. Effectiveness of water fluoridation in caries preventions. Community Dent Oral Epidemiol, v. 40, n. 2, p. 55-64, 2012. 10.1111/j.1600-0528.2012.00721. 
SOARES, Marta Desire do Carmo Moreira; GASPAR, Márcia Regina; PEREIRA, Antonio Carlos; MOREIRA, Ben Hur Wey. Localidades com diferentes concentrações de flúor nas águas de consumo e sua relação com a prevalência de fluorose. Odontol Mod. v. 22, n. 4, p.18-21, out./dez. 1995.

WILLIAMSON, Mark M. Endemic dental fluorosis in Kenya: a preliminary report. East African Medical Journal, v.30, n. 6, p. 217-233, Jun. 1953.

WORLD HEALTH ORGANIZATION - WHO. Fluorine and fluorides. Geneve: WHO, 1984 (Environmental health criteria; 36). Disponível em: <http:// http://apps.who.int/iris/ handle/10665/37288>. Acesso em: 12 jan. 2016.

YOUNG, Nicholas; NEWTON, John; MORRIS, John; MORRIS, Joan; LANGFORD, John; ILOYA, Jonathan; EDWARDS, Diane; MAKHANI, Semina. Community water fluoridation and health outcomes in England: a cross-sectional study. Community Dent Oral Epidemiol, v. 43 , n. 6 , p. 550-559. 2015. 10.1111/cdoe. 12180 .

Celso Zilbovicius - Doutor e mestre em Ciências Odontológicas (Odontologia Social ) pela Universidade de São Paulo (USP); graduado em Odontologia pela USP. Professor-doutor do Departamento de Odontologia Social da Faculdade de Odontologia da USP. São Paulo/SP, Brasil.E-mail: czilbo@usp.br.

Regina Glaucia Lucena Aguiar Ferreira - Doutora em Saúde Pública pela Universidade de São Paulo; mestre em Saúde Pública pela Universidade Federal do Ceará (UFC); especialista em Planejamento e Supervisão do Ensino Superior pela Universidade de Fortaleza; graduada em Odontologia pela UFC. Professora adjunta do Departamento de Odontologia Restauradora da UFC. Fortaleza/CE, Brasil. E-mail: reginalucena1@hotmail.com.

Paulo Capel Narvai - Livre-Docente, doutor e mestre em Saúde Pública pela Universidade de São Paulo (USP); doutor em Saúde Pública pela USP; graduado em Odontologia pela Universidade Federal do Paraná. Professor Titular da USP; coordenador do Curso de Especialização em Saúde Pública da USP. São Paulo/SP, Brasil. E-mail: pcnarvai@usp.br. 